\title{
EDUCAÇÃO AMBIENTAL: UM OLHAR SOBRE COMUNIDADES QUILOMBOLAS NA REGIÃO CENTRAL DO RIO GRANDE DO SUL
}

\author{
Beranice Farias de Moura ', Paulo Edelvar Peres², Jorge Orlando Cuellar Noguera², \\ Paulo Romeu Machado ${ }^{2}$ \\ ${ }^{1}$ Especialista em Educação Ambiental \\ ${ }^{2}$ Professores do Curso de Especialização em Educação Ambiental da UFSM
}

\section{RESUMO}

O artigo tem por objetivo de levantar as questões ambientais e de saúde vivenciadas pelas comunidades quilombolas da região central do Estado do Rio Grande do Sul, buscando pesquisar e propor a execução de um programa de atenção às necessidades de saúde detectadas através de observações relacionadas à educação ambiental e saúde, para as comunidades quilombolas. $O$ estudo descreve o Programa do governo Federal ProNEA-Programa Nacional de Educação Ambiental, PEAC -Programa de Educação Compartilhado da Secretaria do Estado do Rio Grande do Sul e o Projeto Pilão-Presença Negra no Campo, desenvolvido pela Universidade Federal de Santa Maria, UFSM. Faz referência em especial à Comunidade Quilombola de Ernesto Penna Carneiro, localizada no distrito de Palma, Santa Maria, RS. A atenção à Saúde da população com ênfase em educação ambiental. Para a realização da presente pesquisa utilizou-se de pesquisa bibliográfica e documentação fotográfica, bem como pesquisa de campo(observação). A última teve o caráter de comparar os estudos teóricos com a realidade da comunidade quilombola Ernesto Penna Carneiro.

Palavras-chave: projetos ambientais; quilombos; saúde.

\section{ABSTRACT}

In the late nineteenth century was signed by Princess Isabel on May 13, 1888 the law Aurea, freeing all slaves. Aiming to raise questions and envi-ronmental health experienced by the maroon communities of the central region of Rio Grande do Sul, this study aimed to research and propose the imple-mentation of a program of care to the health needs identified through comments related to environmental education and health, for the maroon communities. The study describes the program of government-Federal ProNEA National Environmental Education Programme, ECCP-Sharing Education Programme of the Secretariat of Rio Grande do Sul and the project-pylon Black Presence in the Field, developed by Universidade Federal de Santa Maria, RS, Brazil. Makes refer-ence in particular the Community Quilombola Penna Ernesto Carneiro, located in the district of Palma, Santa Maria. Health Care for the population with emphasis on environmental education. To perform this research used literature search and photographic documentation as well as research cam-po (observation). The latter had the character to compare with the theoretical rea-bility of quilombo Ernesto Carneiro Penna.

Keywords: Environmental Projects; Quilombos; Health. 


\section{INTRODUÇÃO}

A educação ambiental constitui-se um tema de relevância social predominantes nos assuntos contemporâneos sendo que a sociedade não pode levar em conta só o momento atual, precisa pensar nas ações a serem realizadas.

No Brasil, a ameaça a biodiversidade está presente em todos os biomas em decorrência do desenvolvimento desordenado e das atividades produtivas. A degradação do solo, a contaminação dos recursos hídricos são alguns dos efeitos nocivos observados.

Associa-se a esses fatos um quadro de exclusão social e elevado nível de pobreza de grande parte da população no país. Muitas pessoas moram em áreas de riscos, como encostas, „margens de riose, etc.

O reconhecimento internacional do fazer educativo como estratégia para se construir sociedades sustentáveis remonta 1972, em Estocolmo, quando foi instituído o Programa Internacional de Educação Ambiental (PIEA ), sob os auspícios da Organização das Nações Unidas para a Educação e a Cultura (UNESCO) e do Programa das Nações Unidas para o Meio Ambiente (PNUMA), em atendimento à recomendação 96 da Conferência de Estocolmo.

Em 1977 foi realizada a Conferência Intergovernamental sobre Educação Ambiental, conhecida como Tbilisi, neste momento estabeleceram as finalidades, objetivos, princípios e as estratégias do PIEA, o qual tem por uma das finalidade a promoção da educação ambiental. Para relembrar que a Educação Ambiental no Brasil surgiu antes da institucionalização na esfera federal.

\section{DESENVOLVIMENTO}

\subsection{Programas Nacional de Educação Ambiental}

O ProNEA é um documento, que foi construído e sintonizado com o Tratado de Educação Ambiental para Sociedades Sustentáveis e Responsabilidade Global. Esse apresenta as diretrizes, os princípios, os objetivos, a delimitação, suas linhas de ação e a missão que orientam as ações da estrutura organizacional.

No Brasil a ameaça à biodiversidade está presente em todos os biomas, em decorrência, principalmente, do desenvolvimento desordenado e desenfreado de atividades diversas. Devido a esses fatos constata-se uma série de agravantes negativos, Também é possível verificar nos centros urbanos, os resíduos sólidos ainda são depositados em lixões, a céu aberto. Associa-se a isso um quadro de exclusão social e elevado nível de pobreza da população.

Para o enfrentamento da problemática ambiental há necessidade de estratégias, sendo que para surtirem o efeito desejável na construção de sociedades sustentáveis, envolvem articulação coordenada entre todos os tipos de intervenção ambiental direta, incluindo as ações em educação ambiental. Dessa forma é possível as medidas políticas, jurídicas, técnico-científicas, institucionais e econômicas voltadas à proteção, recuperação e melhoria socioambiental despontam para as atividades na área educativa (BRASIL, ProNEA,2005)

Coube aos sistemas sociais o desenvolvimento de funções de acordo com as suas atribuições específicas, respondendo às múltiplas dimensões da sustentabilidade, buscando superar os obstáculos da exclusão social e da má distribuição da riqueza produzida no país. É preciso a garantir o 
efetivo controle e a participação social na formulação e execução de políticas públicas, de forma que a dimensão ambiental seja sempre considerada (BRASIL- ProNEA, 2005).

E nesse contexto, que os sistemas sociais atuam na promoção da mudança ambiental, a educação assume posição de destaque para construir os fundamentos da sociedade sustentável, esta apresenta uma dupla função a essa transição societária, ou seja, deverá propiciar os processos de mudanças culturais em direção à instauração de uma ética ecológica e de mudanças sociais em direção aos indivíduos, grupos e sociedades que se encontram em condições de vulnerabilidade em face dos desafios da contemporaneidade.

\subsection{Programas de Educação Ambiental Compartilhado (PEAC)}

O PEAC visa à promoção a formação de agentes prevencionistas, orientar a execução de projetos socioambientais, estimular a cultura da prevenção e a implementação de ações que conduzam às mudanças comportamentais, ao desenvolvimento sustentável e à melhoria da qualidade de vida das populações. Os programas são realizados por meio de parceria entre o Governo do Estado e empresas públicas e privadas, que desenvolvem ações de gestão ambiental interna e voltadas para as comunidades nas quais estão inseridas e são coordenados pelas Secretarias de Estado da Educação (SE) e do Meio Ambiente (SEMA). O PEAC como é chamado mantém interface com os Programas Escola Aberta para a Cidadania e Escola de Tempo Integral da SE e com o Programa Pró-Mar-DeDentro da SEMA. As ações do PEAC - integram o projeto Nossas Cidades de Programa Estruturante do Governo do Estado.

\subsection{Comunidades Quilombolas Versus Conquistas na Legislação}

Quando se trata de Quilombos, é necessário referir-se a história brasileira, com relação à época da escravidão, pois, foram com a fuga dos escravos dos engenhos de cana-de-açúcar e seus descendentes que se criaram as pequenas propriedades de cultivos diversos, os chamados Quilombos. Também, nome proposto para indicar a situação dos negros atualmente em diferentes regiões e contextos do Brasil.

Destaca-se aqui o programa Brasil Quilombola do Governo Federal criado como uma política de Estado para essas comunidades, abrangendo um conjunto de ações integradas entre diversos órgãos governamentais. O direito a terra e ao desenvolvimento econômico e social passaram a ser reais e assumidos como prioridade governamental. As ações são coordenadas pela Secretaria e Políticas de Promoção de Igualdade Racial (SEPPIR), por meio da Subsecretaria de Políticas para Comunidades Tradicionais.

\subsubsection{A Cor da Cultura}

A Cor da Cultura é um projeto educativo de valorização da cultura afro-brasileira por meio de programas audiovisuais. É fruto da parceria do MEC,da Fundação Cultural Palmares, Canal Futura, Petrobras e Centro de Informação e Documentação do Artista Negro (CIDAN). Foi iniciado em 2004, o projeto está apoiado na Lei 10.639 de 2003, que estabelece o ensino da história da África e dos negros nas escolas brasileiras.

\subsubsection{Programa Brasil Quilombola}




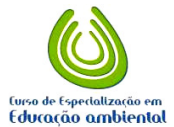

REMOA

\section{Monografias Ambientais}

(Revista Eletrônica do PPGEAmb-CCR/UFSM) ISSN:

As metas e recursos do Programa Brasil Quilombola envolvem 23 ministérios e órgãos federais. Os objetivos do programa são: garantia do acesso a terra, ações de saúde e educação, construção de moradias, eletrificação, recuperação ambiental, incentivo ao desenvolvimento local, pleno atendimento das famílias quilombolas pelos programas sociais, como a Bolsa Família e medidas de preservação e promoção das manifestações culturais quilombolas. As principais realizações do Programa estão: Regularização fundiária, Certificação, Luz para Todos, Bolsa Família e o Desenvolvimento local.

A Universidade Federal de Santa Maria (UFSM) desenvolve um Programa nas Comunidades Quilombolas de Arnesto Penna Carneiro, do Barro Vermelho e Cerro do Louro, o qual leva o nome de Projeto Pilão Presença Negra no Campo.

O Projeto Pilão nasceu do Grupo de Trabalho, Cidadania e Ação e Universidade Federal de Santa Maria, em 2005 movidos pelos problemas existentes nestas Comunidades. Foram/São desenvolvidas atividades diversificadas com a finalidade de elevar a qualidade de vida destas comunidades. Foram/São desenvolvidas oficinas, palestras contemplando as temáticas na área da alimentação, trabalho e saúde. Segundo (SPIAZZI APUD LEITE 2004,p. 83), "a Comunidade [...] constitui-se, portanto, a partir de uma formação social e histórica singular, através dos laços de parentesco, de uma memória e cotidiano comuns, no que denominou "territorialidade negra”. A Comunidade Arnesto Penna Carneiro, ocupa hoje uma área de 1,25 hectares, estando cercados por plantações de soja, trigo e arroz, de propriedade de famílias descendentes, sendo conhecida e reconhecida como "Comunidade Negra" e como "Comunidade Quilombola", pelos diversos agentes externos, entre eles a Prefeitura de Santa Maria, Movimento Negro de Santa Maria, a Imprensa local e pela Fundação Cultural Palmares.

A educação ambiental é um processo de aprendizado, é a comunicação de questões relacionadas à interação do homem com o ambiente natural, é um instrumento de formação de uma consciência pelo conhecimento e reflexão sobre a realidade. Constitui em "um direito de todos terem um ambiente sadio e é um dever de todos preservá-los" (SENAR, p.21).

O principal eixo de atuação da educação ambiental e na saúde consiste em buscar acima de tudo a solidariedade, a igualdade e o respeito à diferença através de formas democráticas de atuação baseadas em práticas interativas e dialógicas. Isto se consubstancia no objetivo de criar novas atitudes e comportamentos na sociedade e de estimular a mudança de valores individuais e coletivos (JACOBI, 1997).

O compromisso com a construção de cidadania pede necessariamente uma prática voltada a compreensão da realidade social e dos direitos e responsabilidades em relação à vida pessoal e coletiva. Segundo BRASIL (1998, p.180).

A questão ambiental impõe às sociedades a busca de novas formas de pensar e agir individualmente e coletivamente, de novos caminhos e produções de bens para suprir as necessidades humanas, e relações sociais que não perpetuem tantas desigualdades e exclusão social, e, ao mesmo tempo garantam a sustentabilidade ecológica.

Em todas as reuniões e encontros com autoridades locais, estaduais, nacionais e ou internacionais as principais recomendações assumidas é de investir numa mudança de mentalidade, conscientizando os grupos humanos a necessidade de adotar ponto de vista e novas posturas diante das ações que vem ocorrendo de agressão ao meio ambiente (BRASIL, 1998).

A preocupação em relacionar a educação ambiental com a vida (...), seu meio, sua comunidade vem crescendo desde a década 60 no Brasil. Exemplo disso são as atividades com os "estudos do meio". Porém a partir da década de 70 , passou-se a utilizar a expressão "educação 
ambiental", para qualificar iniciativas de universidades, escolas, instituições governamentais e não governamentais por meio das quais se buscava conscientizar setores da sociedade para as questões ambientais. Um passo importante foi dado com a Constituição de 1988, no seu Artigo 225 , quando a Educação Ambiental se tornou exigência a ser garantida pelos governos federal, estadual e municipal (BRASIL, 1998).

O Documento "Nosso Futuro Comum" de 1987, da Comissão Mundial sobre o Meio Ambiente e o Desenvolvimento da ONU, apresenta uma visão critica do modelo de desenvolvimento adotado pelos países em desenvolvimento. O referido documento ressalta o uso excessivo dos recursos naturais sem considerar a capacidade do suporte dos ecossistemas e aponta a incompatibilidade entre desenvolvimento e os padrões de produção e consumo adotados atualmente pela sociedade.

A Agenda 21 sugere que haja limites para o desenvolvimento que devem ser respeitados.Tecnicamente é possível prever as necessidades mínimas de cada população, sem a continuidade da degradação dos ecossistemas globais (RIO GRANDE DOSUL, SENAR, 2003).

O desenvolvimento sustentável é definido como aquele capaz de satisfazer as necessidades da geração atual, sem comprometer a capacidade das gerações futuras de suprir suas próprias necessidades.

O desenvolvimento sustentável é o desenvolvimento economicamente viável adequado e socialmente justo para a humanidade. Para ser alcançado, depende do planejamento em longo prazo e do reconhecimento de que os recursos naturais da Terra são finitos e pertence a toda a população. Não se trata de romper com o crescimento, mas de eleger um caminho que garanta o desenvolvimento integrado e participativo e que considere a valorização e o uso racional dos recursos que existem na natureza (SENAR, 1998).

A história se acelera tudo se move rapidamente, são estabelecidas tantas frentes que mal consegue acompanhar. Na última década do século XX, a população passou de 2,1 para 6,1 bilhões de pessoas: duas gerações que produziram mais seres humanos que toda a população junta. Com maior aumento ocorrendo nos países pobres, observa-se a população suplantar a disponibilidade de água, a demanda de lenha e madeira, superar a renovação das florestas e a necessidade de alimentos incompatível com a área local cultivada.

A agilidade do crescimento econômico trouxe reflexos sobre outros recursos naturais, como o aumento da poluição e exploração de recursos hídricos, a extinção de espécies, a destruição de ecossistemas, o desflorestamento, a erosão, etc.

A redução da disponibilidade de água pelo desperdício quanto pela poluição, se configura entre os problemas mais graves. Sabe-se que todas as atividades humanas e todas as formas de vida dependem da água, este é um recurso que merece preocupação. O consumo per capita de água tem aumentado nas últimas décadas. O rebaixamento do nível dos lençóis freáticos verificado em diversas regiões do mundo reduz o armazenamento e a produção de água que alimenta os rios e sustenta as florestas, as lavouras e os seres humanos.

Para que uma transformação efetiva aconteça, é urgente a mudança de comportamento individual e a reformulação de concepção de valores e a educação ganha campo de destaque. A sociedade civil é um campo fértil para provocar ou induzir mudanças (...) tanto pela pressão pela produção menos impactantes de seus bens de consumo como a consciência de limitar o consumo, ampliar o reuso e incentivar a prática de reciclagem, minimizando a produção de resíduos e a pressão pela disposição final. Neste sentido, os professores ganham status de encorajadores do comportamento sustentável (SENAR, 1998). 


\section{METODOLOGIA}

Diante das reflexões anteriores que a pesquisa buscou conhecer a Comunidade Quilombola denominada de Arnesto Carneiro Penna também conhecida pelo nome de Recanto dos Evangélicos e ou Quilombo da Palma, a qual, é uma unidade residencial localizada no bairro Palma, em Santa Maria (RS) distante a 19 km de Santa Maria na região leste do município de Santa Maria no Rio Grande do Sul.

Na Comunidade do Quilombo Arnesto Carneiro Penna possui atualmente 53 pessoas, sendo que dessas 4 são adultos e analfabetos, 10 possuem o ensino fundamental completo, 38 possuem ensino fundamental incompleto e 1 descendente da comunidade cursa o nível superior - DireitoUlbra de Santa Maria (programapilao.blogspot.com/2009).

Nas Comunidades Quilombolas são comuns as atividades relacionadas com a agricultura e a pecuária. Da pecuária origina muitos produtos, tais como o queijo, a nata, a banha, etc. Os animais devem ser bem tratados a fim de que os produtos sejam de qualidade e seguro para o consumo humano. Segue breve revisão sobre as doenças que provém de alguns animais.

As doenças ou infecções causadas pela transmissão de animais vertebrados e o homem ou vice-versa, são chamadas de zoonoses, um dos fatores que contribui para a contaminação é o avanço da agricultura e da pecuária e o contato freqüente com animais de estimação. Por isso, o conhecimento sobre agentes e a sua conta com animais de estimação. Por isso, o conhecimento sobre agentes e a sua contaminação são assuntos importantes para a prevenção. A zoonose é muito conhecida como toxoplasmose, isto é, doença causada pelo protozoário Toxoplasma gondii, a forma de contaminação mais conhecida é o consumo de carnes mal preparadas, porém, o leite cru e queijos não pasteurizados, também pode ser um contaminador de protozoários taquizoítos.

Segundo o artigo publicado por Simeão (2008) salienta que os animais contaminados ao defecarem em locais com boas condições ambientais: calor e umidade fazem com que o ciclo de contaminação se inicie, pois, qualquer animal saudável, ou mesmo os humanos poderão ser contaminados.

A contaminação pode incidir tanto de forma oral como através da pele, quando um animal em gestação que esteja contaminado poderá impregnar seus filhotes através da placenta, ou pelo leite, esta contaminação é conhecida como contaminação de forma direta. No entanto, a forma indireta, refere-se a transmissão através da água, alimentos que estejam contaminados por ovos ou cistos de parasitas, bem como a ingestão de insetos, roedores, lagartixas e outros, que podem ser portadores de parasitas.

No caso de animais de estimação (Simeão apud, Daniela Pontes Chiebão, novembro, 2008) uma das mais eficazes formas de prevenção ou de ação contra os vermes é a utilização de vermífugos, cuidados com a higienização do local de abrigo do animal, além de cuidados com água, comida.

A situação em que o planeta se encontra é de extrema crítica em relação a fatores internos e externos que englobam e propiciam a situação de equilíbrio à sustentação da vida no planeta. A contaminação do solo não afeta somente as plantas ou a população que ali habita, mas sim, a água, o ar e a vegetação, a contaminação atinge de forma ampla outros elementos da natureza. Assim, o solo elemento da natureza que possui características que demonstram o estado real em que o mesmo se encontra atualmente.

Segundo Miranda (2007), afirma que é um tempo cauteloso no que se trata da problemática ambiental, sendo no campo ético ou moral, na educação ou da percepção, da história, das 
engenharias, pois os processos e atividades educacionais e humanas que propõem o conhecimento para ações e deveres de cidadania.

\section{CONCLUSÃO}

Para busca de aprofundamento dos programas, projetos e ou parcerias de educação ambiental e saúde no âmbito nacional, estadual e municipal, identificando se as comunidades quilombolas estavam inseridas e ou se existiam outras leis especificas para estas comunidades, e após a revisão bibliográfica, apresentar uma proposta de saúde com ênfase na educação ambiental voltou-se o interesse desta pesquisa.

No âmbito nacional, o ProNEA cujo caráter prioritário e permanente deve ser reconhecido em todos os governos, onde o eixo norteador é a perspectiva da sustentabilidade ambiental de um pais para todos. Se é para todos, logo é para as Comunidades Quilombolas espalhadas neste Brasil.

O ProNEA propõem um exercício de transversalidade por meios de espaços de interlocução bilaterial e múltipla.Estimula o diálogo interdisciplinar entre as políticas setoriais propiciando ressaltar as práticas de experiências exitosas, com a integração entre professores e técnicos ambientais em programas de formação.

Estas práticas exitosas que o programa nacional prevê podem ser vistas, através da divulgação do Projeto Pilão - Presença Negra no Campo divulgado no blogpot, disponível na internet. Uma parceria que na qual a UFSM está engajada e que tem a participação de vários profissionais que estão na ativa. Estes profissionais tem oportunizado as comunidades quilombolas oficinas diversas, tais como: reciclagem de resíduos sólidos, palestra sobre recursos hídricos, Avaliação e tratamento bucal, entre outros.

Em relação ao Programa PEAC, este visa a formação de agentes prevencionistas, orientação de projetos socioambientais, etc.Tem vários objetivos, entre os quais destaca-se o de uma cultura de prevenção bem como estimular, avaliar e orientar novos projetos. Analisando o programa, incluiu todos independentes de cor, raça, sexo.

As comunidades Quilombolas tem várias conquistas em relação a legislação, não especifica a área da saúde e ou meio ambiente, mas vai além.

A legislação na área da educação coloca que todos os currículos das escolas devem incluir o ensino obrigatório da temática "História e Cultura Afro- brasileira". Já outra lei assegura a regulamentação, delimitação, demarcação e titulação das terras ocupadas por remanescentes de quilombos; etc.

Pela revisão bibliográfica e pela visita realizada na Comunidade Arnesto Carneiro Penna, foi possível verificar que falta infra-estrutura.

Estão distantes do perímetro urbano, residem nesta comunidade pessoas idosas e são doentes, necessitando ser atendidos nos postos de saúde. Muitas vezes não tem acesso às políticas públicas, por não terem conhecimentos e ou devido as dificuldades de se locomover. Apesar de já terem participado de várias oficinas de aprendizagem, ainda precisam ser orientados quanto aos aspectos da higiene pessoal e do próprio local onde moram, pois possuem animais de estimação, muitos deles com doenças que acabam transmitindo as crianças e demais pessoas. Também precisam urgentemente ser encaminhados para um dentista.

As Comunidades Quilombolas tem direito aos serviços da saúde, conforme propõem os sistemas de atenção a saúde, isto é, sejam dirigidos por valores de dignidade, equidade, 
solidariedade, ética profissional, baseados em financiamento sustentável a fim de permitir a cobertura universal a todos que dela precisarem.

Analisando as propostas já mencionadas nos três âmbitos, percebe-se que os professores, diretores, etc. das escolas fazem parte da sociedade como tal e não, podem ficar fora dos projetos e ou programas de educação ambiental e saúde, pois ambos caminham juntos. Para tanto o último capítulo apresentou uma proposta de trabalho a ser desenvolvida numa escola de educação básica. Em função do tempo não foi possível aplicá-la.

Espera-se que esta pesquisa seja um instrumento de apoio às discussões pedagógicas na elaboração de novas propostas de educação na saúde com ênfase na educação ambiental.

\section{REFERÊNCIAS BIBLIOGRÁFICAS}

Abreu, a importância da educação ambiental: sustentabilidade. Disponível em <http://www.atitudessustentaveis.com.br/conscientizacao/a-importancia-da-educacao-ambientalsustentabilidade>.acesso em 14 abr 2010.

BRASIL. Programa Nacional de Educação Ambiental. ProNEA, Ministério do Meio Ambiente, 3a Ed,Brasília:MMA,2005,102p.

BRASIL.SEPPIR

Disponível

em

$<$

http://www.presidencia.gov.br/estrutura_presidencia/seppir/copy_of_acoes/)>. Acesso em abr 2010

BRASIL. Projetos e Ações do Governo Federal.Disponível em http://www.presidencia.gov.br/estrutura.Acesso em 21 de abr 2010.

BRASIL, MEC. Legislação. Disponível em <http://portal.mec.gov.br/mec/index.htm>. Acesso em 21 de abr 2010.

BRASIL. Secretaria Estadual do Meio Ambiente. Disponível em http://www.sema.rs.gov.br/. Acesso em 23 de abr 2010. 14 CANDEIAS, Nelly Martins Ferreira. Conceitos de Educação e de Promoção em saúde: mudanças individuais e mudanças organizacionais. Revista de Saúde Pública, volume31,n2,abr 1997,p.209-23.Disponível em < http://www.UFSM.com.br.Disciplina de Educação Ambiental: Educação e Saúde.

COLEÇÃO SAÚDE, EDUCAÇÃO E PREVENÇÃO. Odontopediatria: Informações científicas para o leigo. Editora Conceito,2005.

FIGURA: 1, ,3,,5 e 6.Disponibilizadas pelo Prof. Dr. Paulo Edelvar Correa Peres em março de 2010.

FIGURAS: 2, 4 e 7 SPIAZZI, Daiane Tonato - Mestranda do Programa de Pós-Graduação Profissionalizante em Patrimônio Cultural pela Universidade Federal de Santa Maria. PADOIN, Maria Medianeira (Professora Doutora Adjunta do Curso de História e do Programa de Pós-Gruação em Patrimônio Cultural da Universidade Federal de Santa Maria. Brasil). Disponível em http://pt.wikipedia.org/wiki/Comunidade_Arnesto_Carneiro_Penna, COMUNIDADE QUILOMBOLA 
ARNESTO PENNA CARNEIRO FRENTE AO PROCESSO DE RECONHECIMENTO E REGULARIZAÇÃO FUNDIÁRIA DAS TERRAS QUILOMBOLAS.

FIGURA 7 . Determinantes do Estado de Saúde I Atenção Primária:Equilíbrio entre necessidades de saúde, serviços e tecnologias. SARTIELD, Barbara, 2002.

LAUTER, Carlos, Kleinvbing, Júlio, Lairton Pedro (Org.) A Educação Ambiental Inovando a Gestão. Programa de Educação Ambiental Compartilhada- PEAC,2006.

CANDEIAS, Nelly Martins Ferreira. Conceitos de Educação e de Promoção em saúde: mudanças individuais e mudanças organizacionais. Revista de Saúde Pública, volume31,n2,abr 1997,p.20923.Disponível em < http://www.UFSM.com.br.Disciplina de Educação Ambiental: Educação e Saúde. 
LIMA, Marcelo Ricardo de. O Solo e o Meio Ambiente. Mini curso realizado durante o IX Encontro Paranaense de Educação Ambiental (EPEA), realizado no período de 1 a 3 de setembro de 2006 em Guarapuava (PR).

LIMA, Lina EDA Martinelli . Saúde - Odontopediatria. ed. Conceito.

MIRANDA, Daniela Janaína Pereira. Educação e Percepção Ambiental: 0 despertar consciente do saber ambiental para a ação do homem na natureza. Rev. eletrônica Mestr. Educ. Ambient. ISSN 1517-1256, v.19, julho a dezembro de 2007.

RIO GRANDE DO SUL. PEAC, livro, 2005. Disponível em< http://www.peac.sema.rs.gov.br/content/downloads.php>. Acesso em 21 abr 2010.

RIO GRANDE DO SUL. PEAC, Apresentação, 2005. Disponível em<http://www.peac.sema.re.gov.br/content/downloads. Acesso em 21 abr 2010.

RIO GRANDE DO SUL Programa de Educação Ambiental Compartilhado. Disponível em < http://sema-rs>. Acesso em 19 de abr 2010.

RIO GRANDE DO SUL. Projeto Pilão - Presença Negra no Campo. Disponível em http://programapilao.blogspot.com/2009_03_01_archive.html>. Acesso em 12 de abri 2010.

RIO GRANDE DO SUL. Seminário Estadual do Meio Ambiente, 2005. Disponível em http://www.peac.sema.rs.gov.br/content/downloads.php. Acesso em 22 abr 2010.

RIO GRANDE DO SUL. SENAR. Programa Agrinho, Uma Leitura para os temas transversais. Ensino Fundamental, 2003, $610 p$.

SEMIÃO, Liliane. Vida e Saúde: Seu Pet sempre saudável. Revista mensal. Ano 70, n 11. ISSN1413082.

SPIAZZI, Daiane Tonato. A Comunidade Quilombola Arnesto Carneiro Penna frente ao processo de reconhecimento e regularização das suas terras Quilombolas. Disponível em < http://wikpedia.org/wiki/Comunidade_Arnesto Carneiro Penna>.Acesso em 20 de abr 2010.

STARFIELD, Barbara, 2002. Atenção Primária: equilíbrio entre necessidades de saúde, serviços e tecnologias, 2002. 